\title{
Male breast cancer: clinicopathological characterization of a National Danish cohort 1980-2009
}

\author{
Anne Marie Bak Jylling ${ }^{1,2} \cdot$ Vibeke Jensen $^{3} \cdot$ Giedrius Lelkaitis $^{4} \cdot$ Peer Christiansen $^{5} \cdot$ Sarah Schulz Nielsen $^{6}$. \\ Marianne Djernes Lautrup ${ }^{5,7}$
}

Received: 29 November 2019 / Accepted: 10 February 2020 / Published online: 27 February 2020

(c) The Author(s) 2020

\begin{abstract}
Background To describe relevant pathological parameters of Danish male breast cancer patients (MBCP) diagnosed from 1980 to 2009, and to relate these data to treatment, overall survival (OS) and standardized mortality rate (SMR).

Materials and methods The MBCP cohort was defined from national Danish registers. A total of $643 \mathrm{MBCP}$ were identified with tissue available in 457 . Among these, 384 were primary operable. Where tissue blocks were available, tumor type, grade, estrogen receptor (ER), progesteron receptor (PgR) and androgen-receptor (AR) status as well as HER 2 and Ki67 were performed. OS was quantified by Kaplan-Meier estimates and SMR was calculated based on mortality rate among patients relative to the mortality rate in the general population.

Results Male breast cancer was more often of ductal type, grade II and a very high proportion were ER and AR positive and HER2 negative. Intrinsic subtypes based on immunohistochemical evaluation showed luminal subtype. Ki67 ratio increased over period of study. OS declined by increased age, bigger tumor size, positive lymph node status, higher grade and Luminal B subtype. Hazard ratio and relative risk of SMR were highest for patients aged $<60$ years.

Conclusion Male breast cancer is of luminal subtype, but more often Luminal B. Ki67 is crucial in evaluation of subtypes by immunohistochemistry, but have limitations. Subtyping seems to be of major importance. AR also can have a role in future treatment.
\end{abstract}

Keywords Male breast cancer $\cdot$ Pathology $\cdot$ Clinicopathological characterization $\cdot$ Intrinsic subtypes

Electronic supplementary material The online version of this article (https://doi.org/10.1007/s12282-020-01066-3) contains supplementary material, which is available to authorized users.

Anne Marie Bak Jylling

Anne.marie.bak.jylling@rsyd.dk

1 Research Unit of Pathology, Department of Clinical Research, University of Southern Denmark, Odense, Denmark

2 Department of Pathology, Odense University Hospital, Odense, Denmark

3 Department of Pathology, Aarhus University Hospital, Aarhus, Denmark

4 Department of Pathology, Rigshospitalet, Copenhagen University Hospital, Copenhagen, Denmark

5 Department of Plastic and Breast Surgery, Aarhus University Hospital, Aarhus, Denmark

6 Danish Breast Cancer Group, Rigshospitalet, Copenhagen University Hospital, Copenhagen, Denmark

7 Department of Surgery, Lillebaelt Hospital, Vejle, Denmark

\section{Introduction}

Male breast cancer represents less than $1 \%$ of all new cases of breast cancer. The incidence is shown to be increasing in certain studies as well as documented in the National Cancer Institute's Surveillance, Epidemiology, and End Results Program (SEER) cancer statistics review (1975-2011) and NORDCAN [1-3]. Men with breast cancer are generally older than female patients [4].

The risk of male breast cancer increases with age [5].

Most former studies report worse outcome for male breast cancer than for female breast cancer based on overall survival. This seems to be correlated to older age at diagnosis, men have shorter expectation of life than women, comorbidity, later diagnosis and more advanced stage [1]. Because of that SMR seems to give a more relevant information.

In general, it is more difficult to do science on a rare disease like MBC because of small study populations and incomplete data because of long study periods including old 
data. Furthermore, different statistical methods for estimating prognosis or survival have been used.

Male breast cancer is often reported to be diagnosed at a later stage than female breast cancer, and differences in tumor biology have also been described [6, 7]. Male breast cancer is associated with BRCA2 gene $[2,5,8]$ and more men have other malignancies $[9,10]$. MBC is more often of ductal origin compared to female breast cancer and is almost always ER positive [11, 12]. Studies made on intrinsic subtypes based on histopathological criteria show that almost all are of luminal subtype and most often Luminal A compared to Luminal $\mathrm{B}$, although results are conflicting [11, 13, 14]. Only very few and small studies doing molecular subtype, based on PAM50, showed Luminal B to be more common [15].

Much effort is made through translational research for showing that clinical, biological, pathologic and genetic parameters not only could be used for generating prognosis estimates, but also could predict the effect of a given form of treatment. Examples of such parameters in breast cancer include ER and endocrine treatment as well as overexpression/amplification of the HER2 receptor and HER2 targeted treatment. Because of small studies and lack of data, men are usually treated in the same way as female breast cancer patients, however, there are no clear recommendations in this area.

\section{Objective}

The purpose of this study is to describe the prognostic and predictive biological and pathological markers, based on examination of collected paraffin-preserved tumor material from a large Danish cohort of male breast cancers in the period from 1980 to 2009.

Beyond that, the aim is to be able to identify areas where it will be relevant to test new, targeted regimes of treatment in prospective studies that may follow.

\section{Patients and methods}

\section{Study population and period}

The patient material was identified from the Danish Cancer Registry for the period 1st January 1980 through 31st December 2009-the same cohort as in a formerly published article presenting clinical data by the same authors [6].

To avoid misclassification, we double checked with two other Danish national registers; The National Patient Register (NPR), and The National Pathology Data Bank (Patobank).
Until now, men were not registered in the Danish Breast Cancer Group (DBCG) database, which only includes female breast cancer patients.

In Denmark, every person is registered with a civil registration number (CPR number) indicating time of birth. This allows for easy identification in any register of the total cohort of male breast cancer patients during the study period. Date of death is registered in the Danish Civil Registration Number System (CPR Register), too. We use the CPR number to link the different registers.

This means that we have complete data according to study population.

This information was used in the survival analyses.

Denmark has a tax-supported public health system providing free hospital care, and all patients treated in a hospital are registered in NPR with a code of diagnosis and a code of treatment supplied with a code of the hospital and the department treating the patient, allowing for identification of the location of the patients' medical forms.

All pathology data from breast cancer patients are registered in Patobank. Patobank contains information in a database (or, for the very early period, in paper form) of all tumor pathology characteristics and lymph node involvement, reported at time of diagnosis.

For each patient identified through the registers, medical records were reviewed region-by-region with the aim to collect data on age, diagnosis (mammography including ultrasonography, clinical examination and biopsies, i.e., triple test), and treatment (surgery-radical/not radical, adjuvant chemotherapy, endocrine therapy and radiation therapy). Based on the available information from the registers and from medical forms, the cases of male breast cancer were classified as early, locally advanced, or disseminated at time of diagnosis. Furthermore, we evaluated from the medical forms if adjuvant therapy was considered sufficient and relevant according to existing guidelines for female patients.

Patients with disseminated disease and locally advanced disease at diagnosis were excluded if they never reached operation and thus, not enough tumor tissue was available.

In such cases, paraffin-embedded tumor tissue was requested from all Danish Departments of Pathology. In some cases, tissue blocks were not available. As expected, the frequency of unavailable tissue samples was higher for the early calendar periods.

Tumor tissue was handled at Department of Pathology, Aarhus University Hospital and all formalin-fixed, paraffinembedded tissue blocks from the primary tumors underwent central pathology review for tumor type and grade, and new immunohistochemical analyses (ICH) were performed.

Patients with non-invasive breast cancer, misclassified breast cancer (for instance, metastases from other primary sites), those treated with neo-adjuvant therapy and patients with no or insufficient tumor tissue left were excluded. 
Furthermore, tumor tissue from all patients diagnosed at private practitioners or departments, which no longer exist, were not available. We were able to collect tumor tissue from 457 out of 643 patients with confirmed diagnosis during the period 1980-2009 and who were alive at diagnosis. 384 of these were considered having early-stage breast cancer and thereby primarily operable (Fig. 1).

\section{TMA preparation and evaluation}

Since 1980, breast cancer treatment has gradually been centralized, and a lot of departments previously treating breast cancer are now closed. Therefore, some of the male breast cancer patients could not be localized and their medical records were not available. These patients remained included, but with missing variables. As expected, the frequency of missing medical records was higher for the early calendar periods.

The most representative tumor block (if more than one) was selected for the study. Whole slides were stained with Hematoxylin and Eosin (HE) and reviewed by three experienced breast pathologists for histological type and malignancy grade according to the modified Bloom-Richardson score $[16,17]$. This slide was also used to identify representative, invasive tumor areas.

For the IHC analyses, tissue microarrays with two cores of $2 \mathrm{~mm}$ per tissue block from this area were obtained and

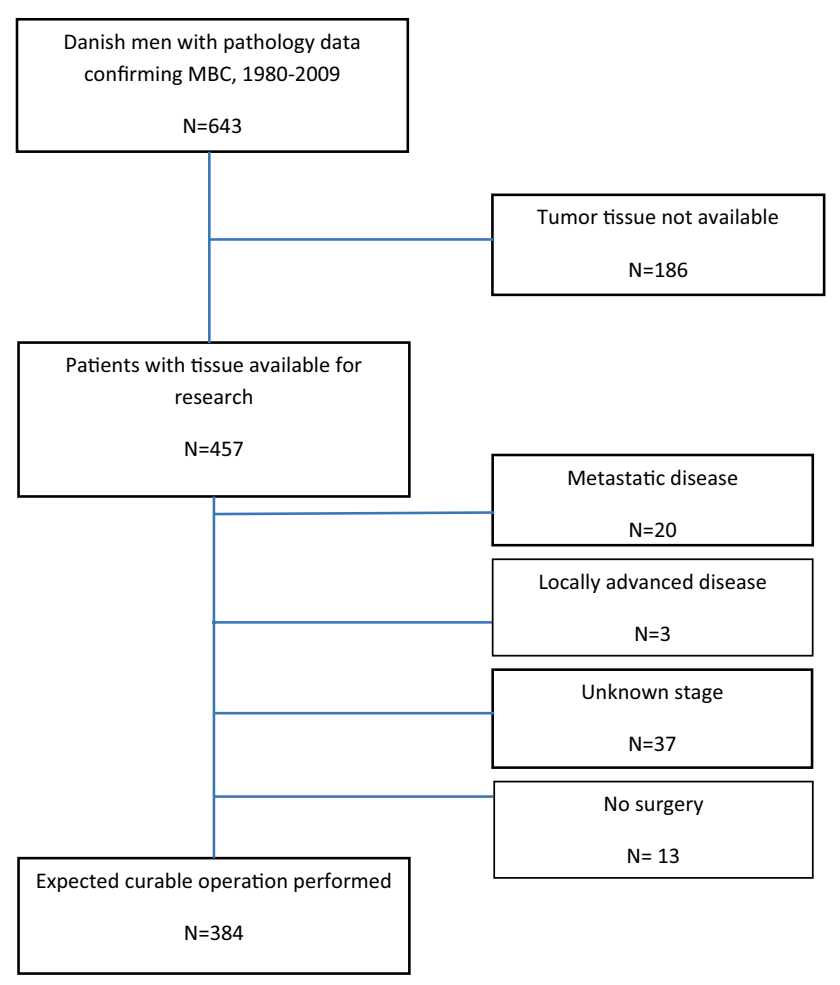

Fig. 1 Danish male breast cancer population. Flow diagram embedded in a recipient paraffin block. Histological sections were cut at $4 \mu \mathrm{m}$ and mounted on Superfrost+ glass slides and stained and scored for ER, PR, AR, HER2 and Ki67. All stains were performed on a fully automated IHC staining machine (BenchMark Ultra, Ventana). Appropriate positive controls were used throughout. HER2 2+ tumors were evaluated using Silver in Situ Hybridization (SISH). All IHC stains were performed in one center and scored in consensus by the same three breast pathologists, to prevent inter-laboratory and inter-observer variability and to assure quality of the data. We found this specifically important for the evaluation of KI67.

Results were considered positive if more than $10 \%$ of the cells were labeled for all markers, except Ki67: low if $<14 \%$ and high if $\geq 14 \%$ according to St. Gallen guidelines of 2013 [18]. HER2 membrane staining was assessed according to the national DBCG guidelines published in 2013 with the following recommendations of HER 2 in breast cancer: negative if $0 / 1+$ and positive if $2+$, ISH confirmed or $3+$.

Intrinsic subtypes were classified according to immunohistochemical panel expression profile as follows:

- Luminal A: ER+ and/or PR+, HER2 negative and Ki67 $<14 \%$

- Luminal B: ER+ and/or PR+, HER2 negative and Ki67 $\geq 14 \%$

- ER+ and PR neg, HER2 negative and any Ki67

- ER+, any PR, HER2 positive, any Ki67

- HER2 enriched: ER - and PR - and HER2 positive

- Triple negative: ER- and PR- and HER2 negative

\section{Statistics}

Associations between characteristics were analyzed by Chisquare of Fischer's exact test.

OS was calculated as the time elapsed from the date of surgery until death from any cause, and were estimated using the Kaplan-Meier method. Time at risk was defined as time from surgery until date of death from any cause, emigration or end of follow-up. Univariate and multivariate Cox regression analyses for OS were performed and hazard ratios were reported. The number of deaths observed was compared with the number of deaths expected, calculated by applying age and calendar year specific male mortality figures of the general Danish population and the corresponding person years of the respective cohort members. The SMR, computed as the ratio of the observed to the expected number of deaths, served as an estimate of relative risk of death, and 95\% confidence intervals (CI) were computed based on the assumption that the observed number of deaths followed a Poisson distribution. The SMR were analyzed 
Table 1 Histopathologic characteristics related to diagnose decade (primary operable)

\begin{tabular}{|c|c|c|c|c|c|c|c|c|}
\hline \multirow[t]{3}{*}{ Characteristics $(N=384)$} & \multirow[t]{3}{*}{ Total } & \multicolumn{6}{|c|}{ Year of operation } & \multirow[t]{3}{*}{ Test $p$ value $^{\mathrm{a}}$} \\
\hline & & \multicolumn{2}{|c|}{$<1990$} & \multicolumn{2}{|c|}{ 1990-1999 } & \multicolumn{2}{|c|}{$2000-$} & \\
\hline & & No & $(\%)$ & No & $(\%)$ & No & $(\%)$ & \\
\hline All patients & 384 & 59 & & 137 & & 188 & & \\
\hline Lymph node status & & & & & & & & 0.001 \\
\hline Negative & 133 & 13 & 22 & 41 & 30 & 79 & 42 & \\
\hline Positive & 182 & 29 & 49 & 64 & 47 & 89 & 47 & \\
\hline Missing & 69 & 17 & 29 & 32 & 23 & 20 & 11 & \\
\hline Tumor size $(\mathrm{cm})$ & & & & & & & & $<0.0001$ \\
\hline$\leq 2$ & 203 & 23 & 39 & 69 & 51 & 111 & 59 & \\
\hline $2.1-4.9$ & 130 & 20 & 34 & 40 & 29 & 70 & 37 & \\
\hline $5+$ & 11 & 5 & 8 & 3 & 2 & 3 & 2 & \\
\hline Missing & 40 & 11 & 19 & 25 & 18 & 4 & 2 & \\
\hline ER & & & & & & & & $0.70 *$ \\
\hline Missing & 10 & 0 & 0 & 5 & 4 & 5 & 3 & \\
\hline$<10 \%$ & 3 & 0 & 0 & 1 & 1 & 2 & 1 & \\
\hline$\geq 10 \%$ & 371 & 59 & 100 & 131 & 95 & 181 & 96 & \\
\hline HER2 & & & & & & & & $0.36^{*}$ \\
\hline Missing & 11 & 0 & 0 & 7 & 5 & 4 & 2 & \\
\hline HER2 normal & 355 & 56 & 95 & 123 & 90 & 176 & 94 & \\
\hline HER2 positive & 18 & 3 & 5 & 7 & 5 & 8 & 4 & \\
\hline PR & & & & & & & & $0.09 *$ \\
\hline Missing & 9 & 0 & 0 & 5 & 4 & 4 & 2 & \\
\hline$<10 \%$ & 58 & 9 & 15 & 28 & 20 & 21 & 11 & \\
\hline$\geq 10 \%$ & 317 & 50 & 85 & 104 & 76 & 163 & 87 & \\
\hline $\mathrm{AR}$ & & & & & & & & 0.46 \\
\hline Missing & 26 & 3 & 5 & 10 & 7 & 13 & 7 & \\
\hline$<10 \%$ & 86 & 18 & 31 & 32 & 24 & 36 & 19 & \\
\hline$\geq 10 \%$ & 272 & 38 & 64 & 95 & 69 & 139 & 74 & \\
\hline Ki67 & & & & & & & & $<0.0001^{*}$ \\
\hline Missing & 12 & 2 & 4 & 7 & 5 & 3 & 1 & \\
\hline$<14 \%$ & 241 & 48 & 81 & 92 & 67 & 101 & 54 & \\
\hline$\geq 14 \%$ & 131 & 9 & 15 & 38 & 28 & 84 & 45 & \\
\hline Type & & & & & & & & 0.53 \\
\hline IDC & 351 & 54 & 92 & 128 & 93 & 169 & 90 & \\
\hline Other & 33 & 5 & 8 & 9 & 7 & 19 & 10 & \\
\hline Grade & & & & & & & & 0.77 \\
\hline 1 & 90 & 10 & 17 & 29 & 21 & 51 & 27 & \\
\hline 2 & 178 & 30 & 51 & 65 & 47 & 83 & 44 & \\
\hline 3 & 93 & 15 & 25 & 35 & 26 & 43 & 23 & \\
\hline Unknown & 23 & 4 & 7 & 8 & 6 & 11 & 6 & \\
\hline Subtype & & & & & & & & $0.39 *$ \\
\hline Unknown & 14 & 2 & 3 & 7 & 5 & 5 & 3 & \\
\hline Luminal A & 194 & 37 & 63 & 67 & 49 & 90 & 48 & \\
\hline Luminal B & 173 & 20 & 34 & 62 & 45 & 91 & 48 & \\
\hline HER2 enriched & 0 & 0 & 0 & 0 & 0 & 0 & 0 & \\
\hline Triple negative & 3 & 0 & 0 & 1 & 1 & 2 & 1 & \\
\hline
\end{tabular}

*Fisher's exact test used instead of $\chi^{2}$

${ }^{a}$ Including unknowns 
Table 2 Histopathologic characteristics related to age at diagnosis (primary operable)

\begin{tabular}{|c|c|c|c|c|c|c|c|c|}
\hline \multirow[t]{3}{*}{ Characteristics $(N=384)$} & \multirow[t]{3}{*}{ Total } & \multicolumn{6}{|c|}{ Age at diagnosis } & \multirow[t]{3}{*}{ Test $p$ value } \\
\hline & & \multicolumn{2}{|c|}{$<60$} & \multicolumn{2}{|c|}{$60-69$} & \multicolumn{2}{|l|}{$70+$} & \\
\hline & & No & $(\%)$ & No & $(\%)$ & No & $(\%)$ & \\
\hline All patients & 384 & 96 & & 97 & & 191 & & \\
\hline Lymph node status & & & & & & & & 0.007 \\
\hline Negative & 133 & 39 & 41 & 36 & 37 & 58 & 30 & \\
\hline Positive & 182 & 51 & 53 & 48 & 50 & 83 & 44 & \\
\hline Missing & 69 & 6 & 6 & 13 & 13 & 50 & 26 & \\
\hline Tumor size $(\mathrm{cm})$ & & & & & & & & 0.59 \\
\hline$\leq 2$ & 203 & 52 & 54 & 54 & 56 & 97 & 51 & \\
\hline $2.1-4.9$ & 130 & 30 & 31 & 29 & 30 & 71 & 37 & \\
\hline $5+$ & 11 & 1 & 1 & 4 & 4 & 6 & 3 & \\
\hline Missing & 40 & 13 & 14 & 10 & 10 & 17 & 9 & \\
\hline ER & & & & & & & & $0.54 *$ \\
\hline Missing & 10 & 3 & 3 & 3 & 3 & 4 & 2 & \\
\hline$<10 \%$ & 3 & 0 & 0 & 2 & 2 & 1 & 1 & \\
\hline$\geq 10 \%$ & 371 & 93 & 97 & 92 & 95 & 186 & 97 & \\
\hline HER2 & & & & & & & & $0.23 *$ \\
\hline Missing & 11 & 4 & 4 & 3 & 3 & 4 & 2 & \\
\hline HER2 normal & 355 & 84 & 88 & 92 & 95 & 179 & 94 & \\
\hline HER2 positive & 18 & 8 & 8 & 2 & 2 & 8 & 4 & \\
\hline PR & & & & & & & & $0.96^{*}$ \\
\hline Missing & 9 & 3 & 3 & 2 & 2 & 4 & 2 & \\
\hline$<10 \%$ & 58 & 15 & 16 & 13 & 13 & 30 & 16 & \\
\hline$\geq 10 \%$ & 317 & 78 & 81 & 82 & 85 & 157 & 82 & \\
\hline $\mathrm{AR}$ & & & & & & & & 0.50 \\
\hline Missing & 26 & 7 & 7 & 6 & 6 & 13 & 7 & \\
\hline$<10 \%$ & 86 & 21 & 22 & 16 & 17 & 49 & 26 & \\
\hline$\geq 10 \%$ & 272 & 68 & 71 & 75 & 77 & 129 & 67 & \\
\hline Ki67 & & & & & & & & $0.75^{*}$ \\
\hline Missing & 12 & 4 & 4 & 4 & 4 & 4 & 2 & \\
\hline$<14 \%$ & 241 & 58 & 61 & 59 & 61 & 124 & 65 & \\
\hline$\geq 14 \%$ & 131 & 34 & 35 & 34 & 35 & 63 & 33 & \\
\hline Type & & & & & & & & 0.11 \\
\hline IDC & 351 & 91 & 95 & 84 & 87 & 176 & 92 & \\
\hline Other & 33 & 5 & 5 & 13 & 13 & 15 & 8 & \\
\hline Grade & & & & & & & & 0.19 \\
\hline 1 & 90 & 25 & 26 & 17 & 17 & 48 & 25 & \\
\hline 2 & 178 & 34 & 36 & 52 & 54 & 92 & 48 & \\
\hline 3 & 93 & 30 & 31 & 22 & 23 & 41 & 22 & \\
\hline Unknown & 23 & 7 & 7 & 6 & 6 & 10 & 5 & \\
\hline Subtype & & & & & & & & $0.83^{*}$ \\
\hline Unknown & 14 & 4 & 4 & 4 & 4 & 6 & 3 & \\
\hline Luminal A & 194 & 47 & 49 & 49 & 51 & 98 & 51 & \\
\hline Luminal B & 173 & 45 & 47 & 42 & 43 & 86 & 45 & \\
\hline HER2 enriched & 0 & 0 & 0 & 0 & 0 & 0 & 0 & \\
\hline Triple negative & 3 & 0 & 0 & 2 & 2 & 1 & 1 & \\
\hline
\end{tabular}

*Fisher's exact test used instead of $\chi^{2}$

${ }^{a}$ Including unknowns 
Table 3 Treatment in the group of primarily operable MBC (relevant treatment according to FBC guidelines)

\begin{tabular}{lll}
\hline & Frequency & Percent \\
\hline Radiation & 86 & 28 \\
Yes & 217 & 72 \\
No & & \\
Chemotherapy & 37 & 12 \\
Yes & 267 & 88 \\
No & & \\
Endocrine therapy & 182 & 60 \\
Yes & 122 & 40 \\
No & & \\
Tamoxifen & 168 & 56 \\
Yes & 130 & 44 \\
No & & 81 \\
Relevant treatment & 243 & 19 \\
Yes & 56 & \\
No & 85 & \\
Unknown &
\end{tabular}

using univariate and multivariate Poisson regression models and relative risk estimates reported. Factors included in the multivariable analyses were year of surgery $(<1990$, $1990-99, \geq 2000)$, age at diagnosis $(<60,60-69, \geq 70)$, tumor size ( $\leq 2 \mathrm{~cm}, 2.1-4.9 \mathrm{~cm}, \geq 5 \mathrm{~cm}$, unknown), nodal status (negative, positive, unknown), histological type and grade (ductal grade I, II, III, unknown, other histological types), HER2 status (normal, positive, unknown), receptor status (ER, PR and AR; all negative, positive, unknown) and Ki67 (low, high, unknown). Separate models were applied substitute ER, PR, HER2 and Ki67 by subtype. A supplementary analysis including information regarding adjuvant treatment was performed. The assumption of proportional hazards was assessed by Schoenfeld residuals. All $p$ values are two sided. Statistical analyses were done using SAS v9.4 (SAS Institute, Inc., Cary, USA).

\section{Results}

The median age for the whole population of male breast cancer patients was 70 years (range 25-93 years) and more than $50 \%$ were older than 69 years $($ no. $=643)$ [6]. Further results from this entire group are presented in Appendix (Table 1 and $2 \mathrm{a}$ and $2 \mathrm{~b}$ ).

For the group of men included in the analysis considered primary operable $(n=384)$, we present the results in Tables 1 and 2 (listed related to decade of diagnosis respectively age at diagnosis).

ER was positive in $97 \%$ and $\mathrm{PR}$ in $83 \%$. AR was positive in $71 \%$.
HER2 was negative in 92\%. Ki67 increased over time: $15 \%, 28 \%$ and $45 \%$ had $\geq 14 \%$ nuclear positivity, respectively, for the three time periods $(p<0.0001)$.

Tumor size declined statistically significantly with $39 \%$ having tumors $\leq 2 \mathrm{~cm}$ in the decade before 1990, and $59 \%$ after the year $2000(p<0.0001)$.

Lymph node status was known in $82 \%$ of all cases, of which $58 \%$ were node positive (macro- or micro-metastases).

(The same results for the group of men with tissue available $(n=457)$, data are presented in the Appendix.)

In the present cohort of early-stage MBC, 384 patients all had a mastectomy. Axillary lymph node dissection or sentinel node procedure was performed in $82 \%$ of all cases. Adjuvant treatment given is described in Table 3.86 patients (22\%) had radiotherapy, 37 (10\%) chemotherapy and 182 (47\%) endocrine therapy. In $243(63 \%)$, the adjuvant treatment given was considered to be according to recommended treatment following guidelines for female breast cancer treated in the same period.

For the cohort of early-stage MBC patients, outcome as overall survival (OS), univariate, there was significant difference in OS depending on age at diagnosis, tumor size, lymph node status, tumor "type and grade" as well as subtype, PR and AR (Fig. 2).

Too few patients were ER negative to make comparison relevant.

No significant difference was demonstrated according to HER2 and KI67.

Data are presented in Fig. 2 as Kaplan-Meier plots.

OS in a multivariate model is presented in Table 4 for the following parameters: year of operation, age at diagnosis, lymph node status, tumor size, tumor type and grade, PR, AR, HER2, Ki67, as well as subtype (based on ER, PR, HER2 and Ki67).

There were statistically significant associations between OS and age at diagnosis, lymph node status, tumor size and AR status.

When looking at SMR in a univariate model, significant associations were found for year of operation, age at diagnosis, tumor size, type and grade as well as PR, HER2, Ki67, lymph node involvement and subtype. No association was found between SMR and AR. Data are presented in Table 5.

In the multivariate model for SMR, significant associations were only found for age at diagnosis, lymph node status, tumor size, PR, and Luminal A and B subtype.

\section{Discussion}

This study represents a large Danish cohort of male breast cancer diagnosed over a period of 3 decades. 

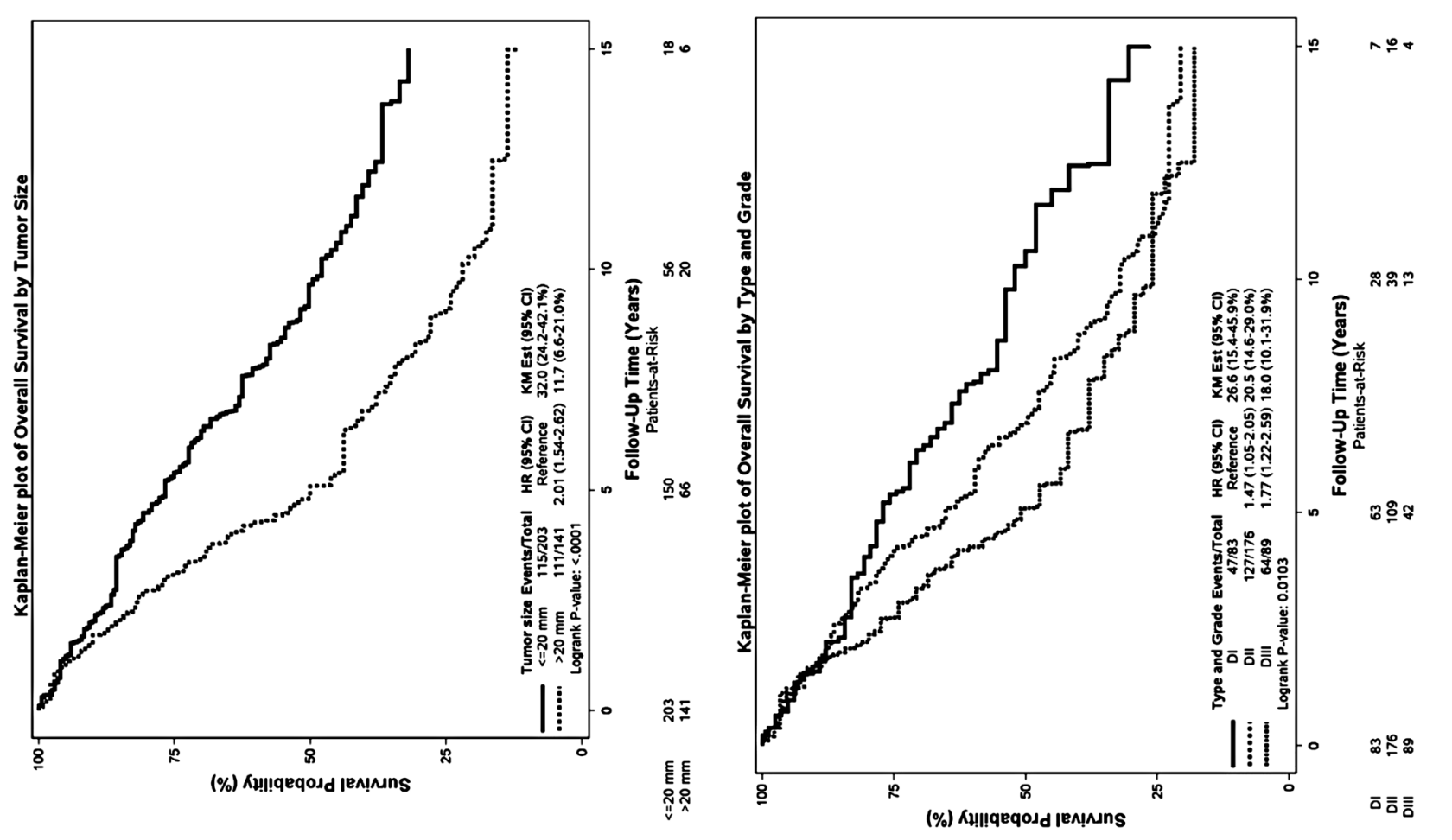

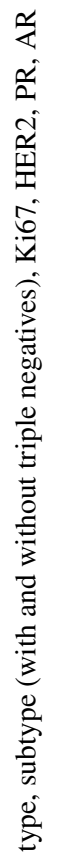
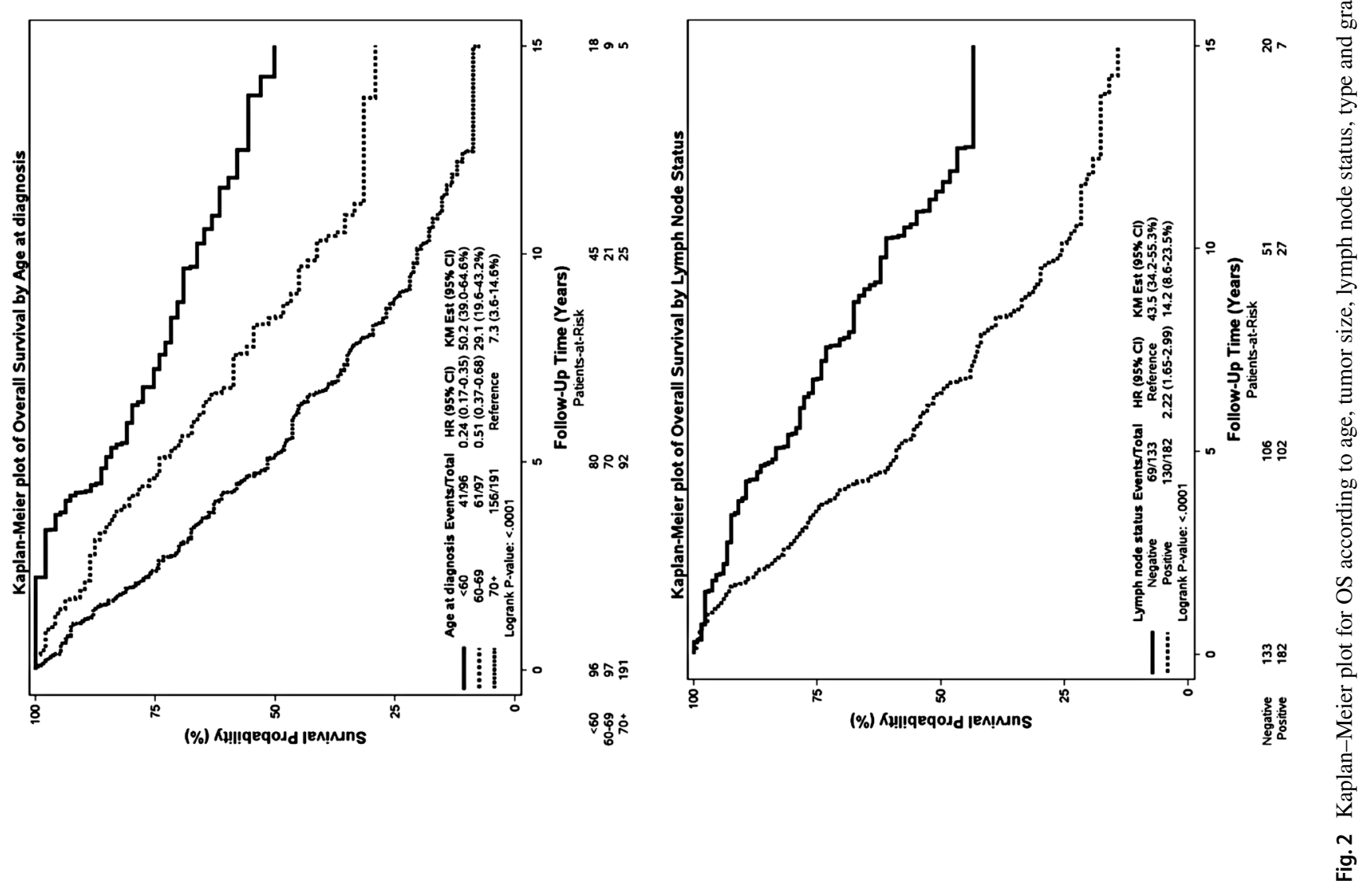

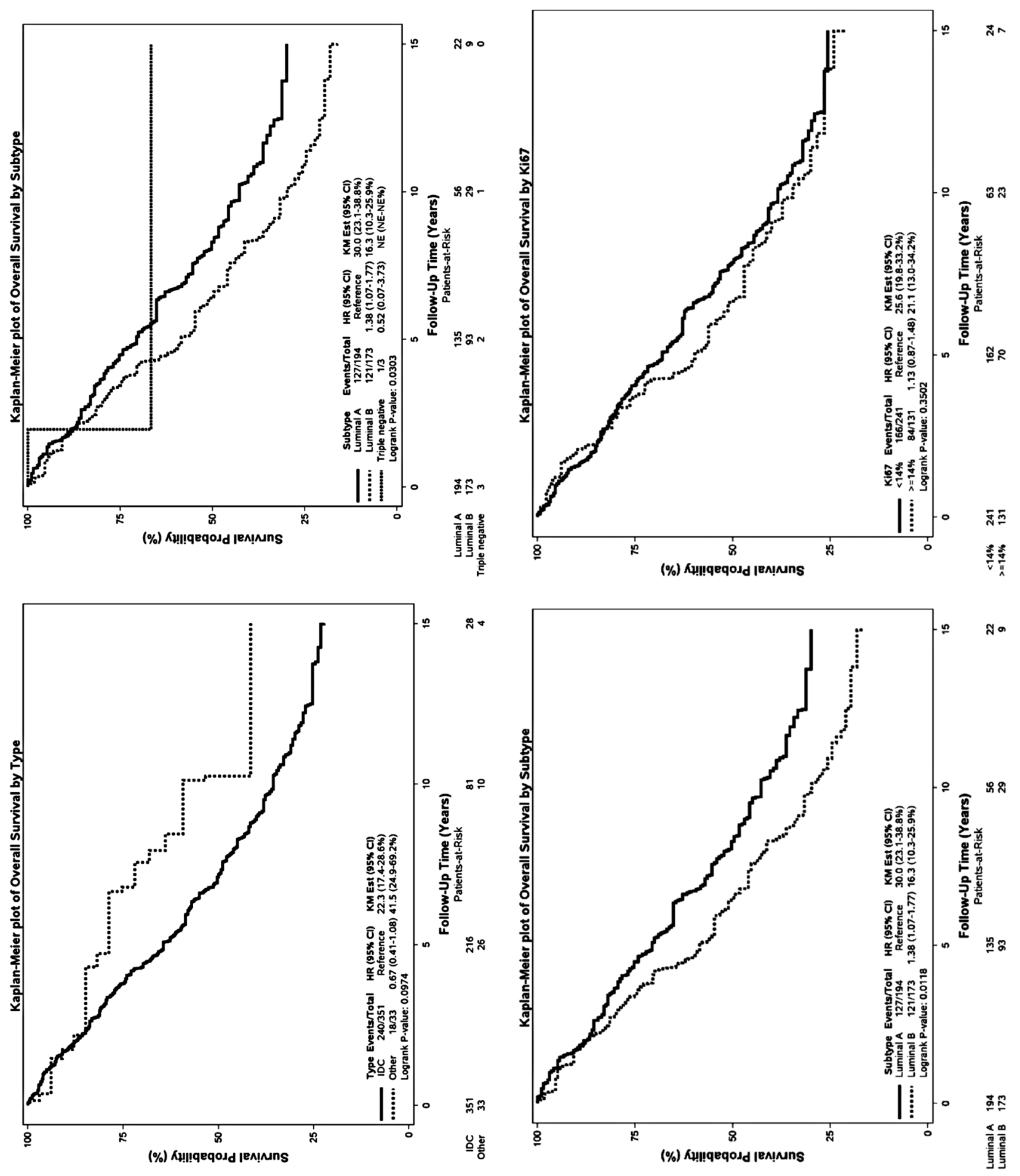

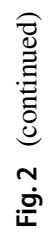




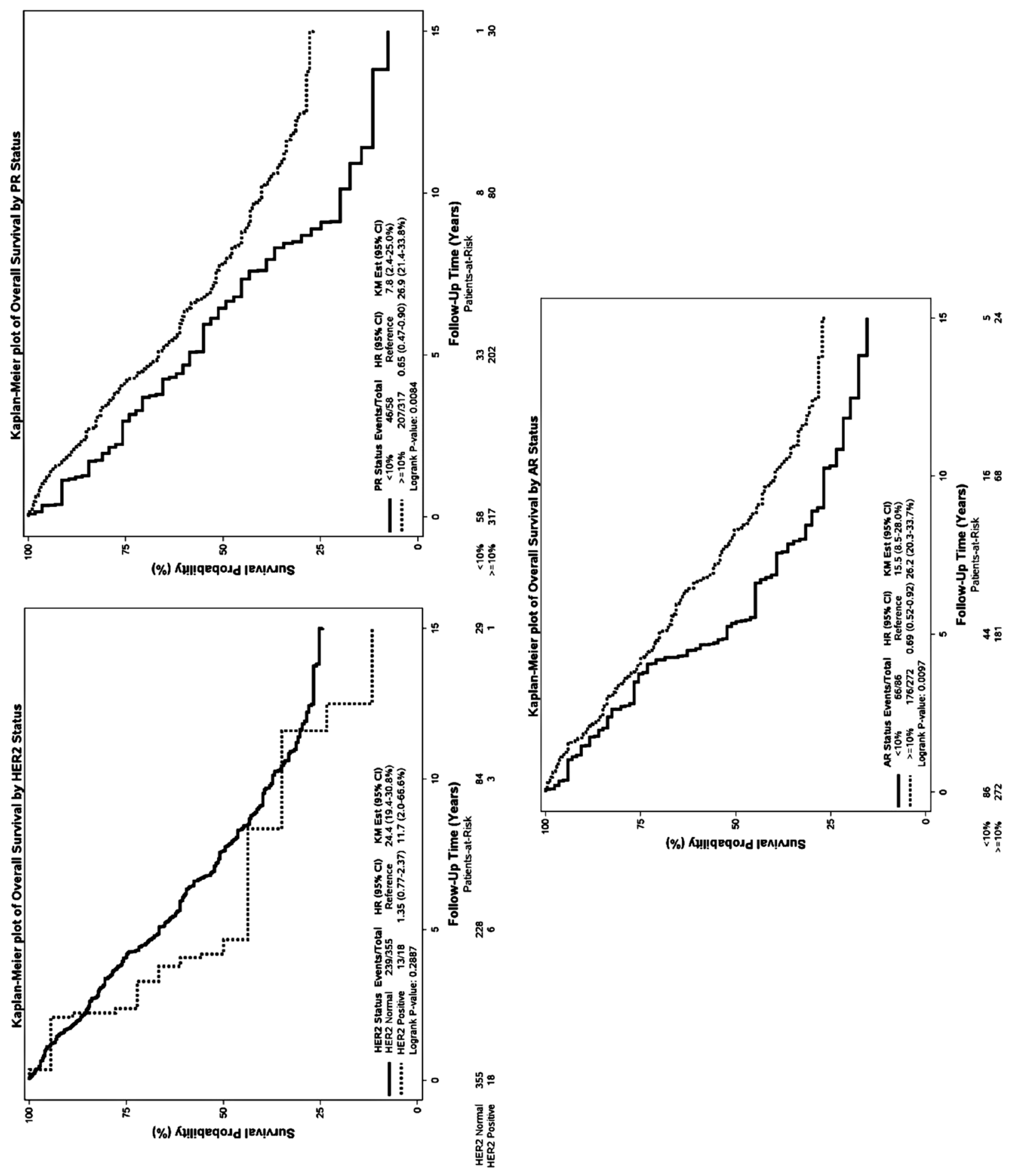


Table 4 Overall survival in a multivariate model

\begin{tabular}{|c|c|c|c|}
\hline \multirow{3}{*}{ Year of operation } & \multicolumn{3}{|c|}{ Overall survival } \\
\hline & HR & $(95 \% \mathrm{CI})$ & $p$ value \\
\hline & & & 0.044 \\
\hline$<1990$ & 1.63 & $(1.11-2.38)$ & \\
\hline 1990-1999 & 1.22 & $(0.89-1.66)$ & \\
\hline $2000-$ & 1 (ref.) & & \\
\hline Age at diagnosis & & & $<0.0001$ \\
\hline$<60$ & 0.22 & $(0.15-0.32)$ & \\
\hline $60-69$ & 0.56 & $(0.41-0.76)$ & \\
\hline $70+$ & 1 (ref.) & & \\
\hline Lymph node status & & & $<0.0001$ \\
\hline Negative & 1 (ref.) & & \\
\hline Positive & 1.98 & $(1.46-2.70)$ & \\
\hline Missing & 1.97 & $(1.35-2.88)$ & \\
\hline Tumor size $(\mathrm{cm})$ & & & $<0.0001$ \\
\hline$\leq 2$ & 1 (ref.) & & \\
\hline $2.1-4.9$ & 1.54 & $(1.17-2.04)$ & \\
\hline $5+$ & 4.27 & $(2.28-8.00)$ & \\
\hline Missing & 1.43 & $(0.93-2.21)$ & \\
\hline HER 2 & & & 0.21 \\
\hline HER2 normal & 1 (ref.) & & \\
\hline HER2 positive & 1.44 & $(0.81-2.57)$ & \\
\hline Missing & 0.89 & $(0.18-4.44)$ & \\
\hline PR & & & 0.08 \\
\hline$<10 \%$ & 1.39 & $(0.96-2.00)$ & \\
\hline$\geq 10 \%$ & 1 (ref.) & & \\
\hline Missing & 0.84 & $(0.15-4.89)$ & \\
\hline $\mathrm{AR}$ & & & 0.02 \\
\hline$<10 \%$ & 1.42 & $(1.06-1.90)$ & \\
\hline$\geq 10 \%$ & 1 (ref.) & & \\
\hline Missing & 1.21 & $(0.61-2.40)$ & \\
\hline Ki67 & & & 0.54 \\
\hline$<14 \%$ & 1 (ref.) & & \\
\hline$\geq 14 \%$ & 1.11 & $(0.80-1.54)$ & \\
\hline Missing & 1.16 & $(0.57-2.38)$ & \\
\hline Type & & & 0.24 \\
\hline IDC & 1 (ref.) & & \\
\hline Other & 0.52 & $(0.17-1.54)$ & \\
\hline Grade & & & 0.39 \\
\hline 1 & 1 (ref.) & & \\
\hline 2 & 1.10 & $(0.78-1.56)$ & \\
\hline 3 & 1.34 & $(0.87-2.06)$ & \\
\hline Unknown & 1.28 & $(0.42-3.86)$ & \\
\hline$\overline{\mathrm{HR}}$ & $(95 \% \mathrm{CI})$ & $p$ value & \\
\hline Subtype & & 0.29 & \\
\hline Luminal A & 1 (ref.) & & \\
\hline Luminal B & 1.24 & $(0.94-1.62)$ & \\
\hline Triple negative & - & - & \\
\hline Unknown & 1.04 & $(0.47-2.30)$ & \\
\hline
\end{tabular}

Multivariate model including year of operation, age at diagnosis, lymph node status, tumor size, HER2 status, PR status, AR status, ki67 status, type and grade and subtype. Unknowns are not included when calculating the $p$ values
We have previously presented the clinical data [6] and here, we present the related clinicopathological characteristics.

MBC was dominated by tumors of ductal type and mostly grade 2 . They were almost exclusively ER positive and of luminal subtypes. All HER2-positive cancers were ER positive, too.

The main strength of this study is that it is based on a national population cohort and that nation-wide survival data were available for a period of 30 years. The Danish healthcare system is tax-supported, free of charge and available to everybody. This system is optimal for national population-based studies, as it gives us a very precise picture of the diagnosis and treatment of all Danish breast cancer patients during the study period. These facts allow for analyses based on data free of selection bias.

The high-quality Danish registers include Statistics Denmark allowing for high quality of SMR analyses. SMR compensates for not having breast cancer specific mortality data.

All available tumor tissue blocks were independently reclassified by three experienced breast cancer pathologists to avoid inter-observer variability assuring quality of the data.

Limitations of the study are the small number of male breast cancer patients, requiring a long study period to include enough patients for statistics to make sense, and, as for most other retrospective studies including more than 30-year-old data, the missing variables especially among the oldest data. The quality of the oldest tissue blocks from the first decade was not as good as the tissue blocks from the last decade. This might have affected the estimation of tumor characteristics.

Our findings are in agreement with several recent studies $[11,12,19]$.

Our results confirm that AR seems to play a role in MBC. This is of special interest, as AR positivity is being studied in ER-positive disease [20]. This receptor could eventually play role in treatment, as it seems to be a new possible treatment target and thereby both a prognostic and predictive marker [4, 21, 22].

The fact that only $63 \%$ got the recommended treatment for female breast cancer (FBC) could reflect the group's compliance that they are men, that they are older and that antihormone treatment probably has even more side-effects for men than for FBC patients, or that their tolerance is lower.

Studies have shown that both OS and disease-free survival (DFS) was significantly affected by low adherence [23, 24]

When looking at standardized mortality rates (SMR) in a univariate model, significant associations were found for year of operation, age at diagnosis, tumor size, type and grade as well as PR, HER2, Ki67, lymph node involvement and subtype. 
Table 5 The effect of patient and tumor characteristics on standardized mortality ratio (SMR) evaluated with crude estimates and with estimates of relative risk in univariate and multivariate Poisson mod- els, including year of surgery, age at diagnosis, lymph node status, tumor size, HER2, PR, AR, Ki67, histological type and grade

\begin{tabular}{|c|c|c|c|c|c|c|c|c|c|c|}
\hline \multirow[b]{4}{*}{ Total } & \multirow{2}{*}{\multicolumn{2}{|c|}{ Number of deaths }} & \multirow{2}{*}{\multicolumn{2}{|c|}{ Crude }} & \multicolumn{6}{|c|}{ Relative risk estimates } \\
\hline & & & & & \multicolumn{3}{|c|}{ Univariate } & \multicolumn{3}{|c|}{ Multivariate } \\
\hline & \multirow{2}{*}{$\begin{array}{l}\text { Observed } \\
258\end{array}$} & \multirow{2}{*}{$\frac{\text { Expected }}{160.6}$} & \multicolumn{2}{|c|}{ SMR $(95 \%$ CI $)$} & \multicolumn{2}{|c|}{ RR $(95 \%$ CI $)$} & \multirow[t]{2}{*}{$p$ value } & \multicolumn{2}{|c|}{ RR $(95 \%$ CI $)$} & \multirow[t]{2}{*}{$p$ value } \\
\hline & & & 1.61 & $(1.42-1.81)$ & & & & & & \\
\hline Year of operation & & & & & & & 0.02 & & & 0.33 \\
\hline$<1990$ & 56 & 27.7 & 2.02 & $(1.56-2.63)$ & 1.65 & $(1.17-2.33)$ & & 1.33 & $(0.91-1.96)$ & \\
\hline 1990-1999 & 115 & 67.4 & 1.71 & $(1.42-2.05)$ & 1.32 & $(0.99-1.75)$ & & 1.08 & $(0.79-1.47)$ & \\
\hline $2000-$ & 87 & 65.5 & 1.33 & $(1.07-1.64)$ & 1 (ref.) & & & 1 (ref) & & \\
\hline Age at diagnosis & & & & & & & $<0.0001$ & & & 0.0001 \\
\hline$<60$ & 41 & 12.8 & 3.20 & $(2.36-4.34)$ & 2.76 & $(1.93-3.95)$ & & 2.18 & $(1.47-3.22)$ & \\
\hline $60-69$ & 61 & 29.7 & 2.05 & $(1.60-2.64)$ & 1.72 & $(1.27-2.33)$ & & 1.71 & $(1.23-2.37)$ & \\
\hline $70+$ & 156 & 118.1 & 1.32 & $(1.13-1.55)$ & 1 (ref.) & & & 1 (ref) & & \\
\hline Lymph node status & & & & & & & $<0.0001$ & & & $<0.0001$ \\
\hline Negative & 69 & 64.5 & 1.07 & $(0.85-1.36)$ & 1 (ref.) & & & 1 (ref) & & \\
\hline Positive & 130 & 50.7 & 2.57 & $(2.16-3.05)$ & 2.57 & $(1.90-3.48)$ & & 1.90 & $(1.37-2.63)$ & \\
\hline Missing & 59 & 45.5 & 1.30 & $(1.00-1.67)$ & 1.24 & $(0.87-1.76)$ & & 1.39 & $0.96-2.01)$ & \\
\hline Tumor size $(\mathrm{cm})$ & & & & & & & $<0.0001$ & & & 0.002 \\
\hline$\leq 2$ & 115 & 92.6 & 1.24 & $(1.03-1.49)$ & 1 (ref.) & & & 1 (ref) & & \\
\hline $2.1-4.9$ & 100 & 51.6 & 1.94 & $(1.59-2.36)$ & 1.59 & $(1.21-2.08)$ & & 1.25 & (0.94-1.68) & \\
\hline $5+$ & 11 & 2.0 & 5.58 & $(3.09-10.08)$ & 4.89 & $(2.61-9.16)$ & & 3.72 & $(1.91-7.23)$ & \\
\hline Missing & 32 & 14.4 & 2.22 & $(1.57-3.14)$ & 1.81 & $(1.22-2.68)$ & & 1.42 & $(0.93-2.17)$ & \\
\hline HER2 & & & & & & & 0.01 & & & 0.11 \\
\hline HER2 normal & 239 & 153.4 & 1.56 & $(1.37-1.77)$ & 1 (ref.) & & & 1 (ref) & & \\
\hline HER2 positive & 13 & 3.7 & 3.48 & $(2.02-6.00)$ & 2.27 & $(1.30-3.98)$ & & 1.66 & $(0.92-2.97)$ & \\
\hline Missing & 6 & 3.5 & 1.71 & $(0.77-3.81)$ & 1.12 & $(0.49-2.51)$ & & 1.01 & $(0.20-5.02)$ & \\
\hline PR & & & & & & & 0.0002 & & & 0.002 \\
\hline$<10 \%$ & 46 & 16.4 & 2.81 & $(2.11-3.75)$ & 1.92 & $(1.39-2.64)$ & & 1.74 & $(1.24-2.45)$ & \\
\hline$\geq 10 \%$ & 207 & 141.0 & 1.47 & (1.28-1.68) & 1 (ref.) & & & 1 (ref) & & \\
\hline Missing & 5 & 3.3 & 1.52 & $(0.63-3.65)$ & 1.04 & $(0.43-2.53)$ & & 0.89 & $(0.13-5.95)$ & \\
\hline $\mathrm{AR}$ & & & & & & & 0.22 & & & 0.09 \\
\hline$<10 \%$ & 66 & 36.3 & 1.82 & $(1.43-2.32)$ & 1.20 & $(0.90-1.59)$ & & 1.32 & $(0.96-1.81)$ & \\
\hline$\geq 10 \%$ & 176 & 115.0 & 1.53 & $(1.32-1.77)$ & 1 (ref.) & & & 1 (ref) & & \\
\hline Missing & 16 & 9.4 & 1.70 & $(1.04-2.78)$ & 1.15 & $(0.69-1.92)$ & & 1.22 & $(0.62-2.40)$ & \\
\hline Ki67 & & & & & & & 0.03 & & & 0.20 \\
\hline$<14 \%$ & 166 & 113.6 & 1.46 & $(1.26-1.70)$ & 1 (ref.) & & & 1 (ref) & & \\
\hline$\geq 14 \%$ & 84 & 43.1 & 1.95 & $(1.57-2.41)$ & 1.35 & $(1.04-1.76)$ & & 1.22 & $(0.90-1.66)$ & \\
\hline Missing & 8 & 3.9 & 2.03 & $(1.01-4.05)$ & 1.40 & $(0.69-2.85)$ & & 1.46 & $(0.57-3.76)$ & \\
\hline Type & & & & & & & 0.005 & & & 0.10 \\
\hline IDC & 240 & 141.0 & 1.70 & $(1.50-1.93)$ & 1 (ref.) & & & 1 (ref) & & \\
\hline Other & 18 & 19.6 & 0.92 & $(0.58-1.46)$ & 0.53 & $(0.33-0.86)$ & & 0.52 & $(0.23-1.16)$ & \\
\hline Grade & & & & & & & $<0.0001$ & & & 0.26 \\
\hline 1 & 50 & 44.3 & 1.13 & $(0.85-1.49)$ & 1 (ref.) & & & 1 (ref) & & \\
\hline 2 & 128 & 75.3 & 1.70 & $(1.43-2.02)$ & 1.57 & $(1.13-2.18)$ & & 1.19 & $(0.84-1.68)$ & \\
\hline 3 & 66 & 24.8 & 2.66 & $(2.09-3.38)$ & 2.46 & $(1.70-3.57)$ & & 1.41 & $(0.93-2.15)$ & \\
\hline Unknown & 14 & 16.2 & 0.87 & $(0.51-1.46)$ & 0.78 & $(0.43-1.42)$ & & 1.30 & $(0.52-3.27)$ & \\
\hline Subtype & & & & & & & 0.0001 & & & 0,02 \\
\hline Luminal A & 127 & 98.5 & 1.29 & $(1.08-1.53)$ & 1 (ref.) & & & 1 (ref.) & & \\
\hline Luminal B & 121 & 55.7 & 2.17 & $(1.82-2.60)$ & 1.72 & $(1.33-2.21)$ & & 1.45 & $(1.10-1.92)$ & \\
\hline
\end{tabular}


Table 5 (continued)

\begin{tabular}{|c|c|c|c|c|c|c|c|c|c|c|}
\hline & \multirow{2}{*}{\multicolumn{2}{|c|}{ Number of deaths }} & \multirow{2}{*}{\multicolumn{2}{|c|}{ Crude }} & \multicolumn{6}{|c|}{ Relative risk estimates } \\
\hline & & & & & \multicolumn{3}{|c|}{ Univariate } & \multicolumn{3}{|c|}{ Multivariate } \\
\hline & Observed & Expected & \multicolumn{2}{|c|}{ SMR $(95 \%$ CI $)$} & \multicolumn{2}{|c|}{ RR $(95 \%$ CI $)$} & \multirow[t]{2}{*}{$p$ value } & \multicolumn{2}{|c|}{ RR $(95 \% \mathrm{CI})$} & \multirow[t]{2}{*}{$p$ value } \\
\hline Triple negative & 1 & 1.2 & 0.86 & $(0.12-6.11)$ & - & - & & - & - & \\
\hline Unknown & 9 & 5.3 & 1.69 & $(0.88-3.25)$ & 1.29 & $(0.66-2.55)$ & & 1.43 & $(0.62-3.31)$ & \\
\hline
\end{tabular}

A separate model was applied substituting ER, PR, HER2 and Ki67 by subtype. $p$ values do not include categories with missing values

This is concordant with SMR for FBC [6], and they are well-known prognostic factors important for the indication of adjuvant treatment.

The overwhelming amount of Luminal subtype is in accordance with former published studies $[11,25]$.

In other studies, Luminal A subtype based on immunohistochemical parameters seems to be the more dominant [13] and is overall also in concord with the present study. However, our study shows that the subtype tends to change from Luminal A towards Luminal B in the later (more recent) decade. The more prominent occurrence of Luminal B in comparison to what is found in female cohorts was also described in a review article from Giordano [25] and in the studies from Cardoso or Vermeulen on EORTC material [11, 19]. Their data are from men diagnosed from 1990 to 2010, thus the two most recent of our decades. The change in our observation concerning the luminal subtypes might reflect the observed change in Ki67,

It has been shown that Ki67 antigenicity is lost more rapidly than other targets of immune stains [26]. This could explain our findings with a higher Ki67 in the last decades compared to the previous (15-28-45\%) and is, therefore, in our opinion, most obviously not a result of changes in the biology of MBC over time.

In addition, there is a well-known inter-laboratory variation in Ki67 evaluation [27], which we have tried to avoid, by three pathologists retesting and evaluating the results together. These findings should be taken into consideration when interpreting distribution of intrinsic subtypes, as Ki67 ratio cut-off is used in subtyping into Luminal A and Luminal B types.

This can, therefore, be crucial when doing immunohistochemical subtyping, especially in older material.

A smaller study of $67 \mathrm{MBC}$ from Sanches-Muñjos, doing PAM50 subtyping based on a 50-gene signature also showed an overweight of Luminal B subtype [15]. This means that we will have to be aware that more men are Luminal B, compared to females with luminal type breast cancer [28].

We found a significantly better SMR for Luminal A subtype than for Luminal B subtype, also well known from female breast cancer [29, 30]. This could indicate the importance of doing molecular subtyping for MBC to distinguish between those patients who will benefit from chemotherapy and those, who will not, if it can be calculated as for postmenopausal FBC.

The small number of MBC means that this will be an affordable task.

It is our intention to do PAM50 on a part of this material as well as tumor-infiltrating lymphocytes (TILS) and BRCA testing in the hope of further characterizing the population.

A better knowledge of this area might contribute to optimizing treatment of $\mathrm{MBC}$ and thereby improving the prognosis.

Acknowledgements We thank The Region of Southern Denmark for a research grant.

Funding The study was supported by the Region of Southern Denmark Research Fund (Grant no. R3-59).

\section{Compliance with ethical standards}

Conflict of interest The authors report no conflict of interest.

Ethical approval The study is approved by The Regional Ethical Committee (no. 1-10-72-479-12), and the Vancouver Convention was respected.

Open Access This article is licensed under a Creative Commons Attribution 4.0 International License, which permits use, sharing, adaptation, distribution and reproduction in any medium or format, as long as you give appropriate credit to the original author(s) and the source, provide a link to the Creative Commons licence, and indicate if changes were made. The images or other third party material in this article are included in the article's Creative Commons licence, unless indicated otherwise in a credit line to the material. If material is not included in the article's Creative Commons licence and your intended use is not permitted by statutory regulation or exceeds the permitted use, you will need to obtain permission directly from the copyright holder. To view a copy of this licence, visit http://creativecommons.org/licenses/by/4.0/.

\section{References}

1. Leone J, Zwenger AO, Leone BA, Vallejo CT, Leone JP. Overall survival of men and women with breast cancer according to tumor subtype: a population-based study. Am J Clin Oncol. 2019;42(2):215-20. 
2. Ferzoco RM, Ruddy KJ. The epidemiology of male breast cancer. Curr Oncol Rep. 2016;18(1):1.

3. NORDCAN: Cancer Incidence, Mortality, Prevalence and Survival in the Nordic Countries, Version 8.2. https://www-dep.iarc. fr/NORDCAN/DK/frame.asp. Accessed 26 Mar 2019.

4. Gucalp A, Traina TA, Eisner JR, Parker JS, Selitsky SR, Park BH, Elias AD, Baskin-Bey ES, Cardoso F. Male breast cancer: a disease distinct from female breast cancer. Breast Cancer Res Treat. 2019;173(1):37-48.

5. Anderson WF, Althuis MD, Brinton LA, Devesa SS. Is male breast cancer similar or different than female breast cancer? Breast Cancer Res Treat. 2004;83(1):77-86.

6. Lautrup MD, Thorup SS, Jensen V, Bokmand S, Haugaard K, Hoejris I, Jylling AB, Joernsgaard H, Lelkaitis G, Oldenburg $\mathrm{MH}$, et al. Male breast cancer: a nation-wide population-based comparison with female breast cancer. Acta Oncol (Stockholm, Sweden). 2018;57(5):613-21.

7. Weir J, Zhao YD, Herman T, Algan O. Clinicopathologic features and radiation therapy utilization in patients with male breast cancer: a national cancer database study. Breast Cancer Basic Clin Res. 2018;12:1178223418770687.

8. Deb S, Lakhani SR, Ottini L, Fox SB. The cancer genetics and pathology of male breast cancer. Histopathology. 2016;68(1):110-8.

9. Zheng G, Yu H, Hemminki A, Forsti A, Sundquist K, Hemminki $\mathrm{K}$. Familial associations of male breast cancer with other cancers. Breast Cancer Res Treat. 2017;166(3):897-902.

10. Serdy KM, Leone JP, Dabbs DJ, Bhargava R. Male breast cancer. Am J Clin Pathol. 2017;147(1):110-9.

11. Cardoso F, Bartlett JMS, Slaets L, van Deurzen CHM, van Leeuwen-Stok E, Porter P, Linderholm B, Hedenfalk I, Schroder C, Martens J, et al. Characterization of male breast cancer: results of the EORTC 10085/TBCRC/BIG/NABCG International Male Breast Cancer Program. Ann Oncol. 2018;29(2):405-17.

12. Masci G, Caruso M, Caruso F, Salvini P, Carnaghi C, Giordano L, Miserocchi V, Losurdo A, Zuradelli M, Torrisi R, et al. Clinicopathological and immunohistochemical characteristics in male breast cancer: a retrospective case series. Oncologist. 2015;20(6):586-92.

13. Kornegoor R, Verschuur-Maes AH, Buerger H, Hogenes MC, de Bruin PC, Oudejans JJ, van der Groep P, Hinrichs B, van Diest PJ. Molecular subtyping of male breast cancer by immunohistochemistry. Mod Pathol. 2012;25(3):398-404.

14. Losurdo A, Rota S, Gullo G, Masci G, Torrisi R, Bottai G, Zuradelli M, Gatzemeier W, Santoro A. Controversies in clinicopathological characteristics and treatment strategies of male breast cancer: a review of the literature. Crit Rev Oncol Hematol. 2017;113:283-91.

15. Sanchez-Munoz A, Vicioso L, Santonja A, Alvarez M, PlataFernandez Y, Miramon J, Zarcos I, Ramirez-Tortosa CL, Montes-Torres J, Jerez JM, et al. Male breast cancer: correlation between immunohistochemical subtyping and PAM50 intrinsic subtypes, and the subsequent clinical outcomes. Mod Pathol. 2018;31(2):299-306.

16. Bloom HJ, Richardson WW. Histological grading and prognosis in breast cancer; a study of 1409 cases of which 359 have been followed for 15 years. Br J Cancer. 1957;11(3):359-77.

17. Elston CW, Ellis IO. Pathological prognostic factors in breast cancer. I. The value of histological grade in breast cancer: experience from a large study with long-term follow-up. Histopathology. 1991;19(5):403-10.

18. Goldhirsch A, Winer EP, Coates AS, Gelber RD, Piccart-Gebhart M, Thurlimann B, Senn HJ. Personalizing the treatment of women with early breast cancer: highlights of the St Gallen International Expert Consensus on the Primary Therapy of Early Breast Cancer 2013. Ann Oncol. 2013;24(9):2206-23.

19. Vermeulen MA, Slaets L, Cardoso F, Giordano SH, Tryfonidis K, van Diest PJ, Dijkstra NH, Schroder CP, van Asperen CJ, Linderholm B, et al. Pathological characterisation of male breast cancer: results of the EORTC 10085/TBCRC/BIG/NABCG International Male Breast Cancer Program. Eur J Cancer (Oxford, England: 1990). 2017;82:219-27.

20. Kono M, Fujii T, Lim B, Karuturi MS, Tripathy D, Ueno NT. Androgen receptor function and androgen receptor-targeted therapies in breast cancer: a review. JAMA Oncol. 2017;3(9):1266-73.

21. Humphries MP, Sundara Rajan S, Honarpisheh H, Cserni G, Dent J, Fulford L, Jordan LB, Jones JL, Kanthan R, Litwiniuk M, et al. Characterisation of male breast cancer: a descriptive biomarker study from a large patient series. Sci Rep. 2017;7:45293.

22. Leon-Ferre RA, Giridhar KV, Hieken TJ, Mutter RW, Couch FJ, Jimenez RE, Hawse JR, Boughey JC, Ruddy KJ. A contemporary review of male breast cancer: current evidence and unanswered questions. Cancer Metastasis Rev. 2018;37(4):599-614.

23. Yadav S, Karam D, Bin Riaz I, Xie H, Durani U, Duma N, Giridhar KV, Hieken TJ, Boughey JC, Mutter RW, et al. Male breast cancer in the United States: treatment patterns and prognostic factors in the 21st century. Cancer. 2020;126(1):26-36.

24. Xu S, Yang Y, Tao W, Song Y, Chen Y, Ren Y, Liu J, Pang D. Tamoxifen adherence and its relationship to mortality in 116 men with breast cancer. Breast Cancer Res Treat. 2012;136(2):495-502.

25. Giordano SH. Breast cancer in men. N Engl J Med. 2018;378(24):2311-20.

26. Combs SE, Han G, Mani N, Beruti S, Nerenberg M, Rimm DL. Loss of antigenicity with tissue age in breast cancer. Lab Investig J Tech Methods Pathol. 2016;96(3):264-9.

27. Penault-Llorca F, Radosevic-Robin N. Ki67 assessment in breast cancer: an update. Pathology. 2017;49(2):166-71.

28. Prat A, Pineda E, Adamo B, Galvan P, Fernandez A, Gaba L, Diez M, Viladot M, Arance A, Munoz M. Clinical implications of the intrinsic molecular subtypes of breast cancer. Breast (Edinburgh, Scotland). 2015;24(Suppl 2):S26-35.

29. Pu M, Messer K, Davies SR, Vickery TL, Pittman E, Parker BA, Ellis MJ, Flatt SW, Marinac CR, Nelson SH, et al. Research-based PAM50 signature and long-term breast cancer survival. Breast Cancer Res Treat. 2019.

30. Nielsen TO, Parker JS, Leung S, Voduc D, Ebbert M, Vickery T, Davies SR, Snider J, Stijleman IJ, Reed J, et al. A comparison of PAM50 intrinsic subtyping with immunohistochemistry and clinical prognostic factors in tamoxifen-treated estrogen receptorpositive breast cancer. Clin Cancer Res. 2010;16(21):5222-32.

Publisher's Note Springer Nature remains neutral with regard to jurisdictional claims in published maps and institutional affiliations. 